Research Article

\title{
Measuring the Energy and Carbon Emission Efficiency of Regional Transportation Systems in China: Chance-Constrained DEA Models
}

\author{
Jianwei Ren $\left(\mathbb{D},{ }^{1,2,3}\right.$ Bin Gao, ${ }^{3}$ Jiewei Zhang, ${ }^{1}$ and Chunhua Chen $\left(\mathbb{D}{ }^{4,5}\right.$ \\ ${ }^{1}$ Transportation Institute, Inner Mongolia University, Hohhot 010070, China \\ ${ }^{2}$ School of Mathematical Sciences, Inner Mongolia University, Hohhot 010010, China \\ ${ }^{3}$ Plymouth Business School, University of Plymouth, Plymouth PL4 8AA, UK \\ ${ }^{4}$ School of Business Administration, Jiangxi University of Finance and Economics, Nanchang 330013, China \\ ${ }^{5}$ Inner Mongolia Branch of Agricultural Bank of China, Hohhot 010010, China \\ Correspondence should be addressed to Chunhua Chen; nmgchenchunhua@126.com
}

Received 24 December 2019; Revised 31 March 2020; Accepted 7 April 2020; Published 21 April 2020

Academic Editor: Huchang Liao

Copyright (c) 2020 Jianwei Ren et al. This is an open access article distributed under the Creative Commons Attribution License, which permits unrestricted use, distribution, and reproduction in any medium, provided the original work is properly cited.

\begin{abstract}
In China, the transportation sector contributes about $18 \%$ of the total carbon emissions. This research contributes to measuring the energy and carbon emission efficiency (ECEE) of regional transportation systems (RTS) in China considering uncertain carbon emissions. A radial chance-constrained data envelopment analysis (DEA) model is developed to estimate the overall efficiency, and a nonradial chance-constrained DEA model is presented to evaluate the pure energy efficiency (PEE) and the pure carbon emission efficiency (PCEE). We prove that the proposed chance-constrained DEA models can effectively address the uncertain carbon emissions when measuring efficiency. We find that most of China's RTS have low ECEE and the inefficiencies are mainly due to the lower gasoline utilization efficiency and the lower kerosene utilization efficiency. In addition, east China performs better than central China, and central China performs better than west China. In China, the unbalanced regional development of the ECEE in transportation corresponds with the unbalanced regional economic development. We provide some valuable suggestions based on the evaluation of the potential cuts in each kind of energy and the potential decreases in carbon emissions.
\end{abstract}

\section{Introduction}

Since China started economic reforms in 1978, the country has been experiencing rapid economic development $[1,2]$. According to the International Monetary Fund (IMF), China had a nominal Gross Domestic Product (GDP) of about 13.37 trillion U.S dollars in 2018. The nominal GDP value of China accounted for approximately 15.7 percent of the global economy [3]. IMF rated China as the largest economy by purchasing power parity (PPP) in the world [4].

China's rapid economic growth has significantly expanded its energy consumption [5]. Therefore, China should make every effort to shift to a green economy. Chinese government has been implementing many policies and measures to increase energy efficiency and reduce carbon emissions. By 2020, China intends to contract carbon dioxide $\left(\mathrm{CO}_{2}\right)$ emissions per unit of GDP by $18 \%$ compared with the level in 2015 [6].

The energy consumption and carbon emissions in the transportation sector are very high $[7,8]$. The total energy consumption in the transportation sector of China was approximately 402 million tons of standard coal equivalent in 2017, an increase of $4.6 \%$ on the previous year. The transportation energy consumption in east China, central China, and west China (the detailed information of the three areas is shown in Section 3) occupied about 49\% (197 million tons), 32\% (127 million tons), and 19\% (78 million tons) of the total energy consumption, respectively. In China, the transportation sector contributes about $18 \%$ of the total carbon emissions [9]. Hence, it is necessary to research the 
energy and carbon emission efficiency (ECEE) of the transportation sector in China.

Several mathematical approaches can be used to evaluate the ECEE. However, data envelopment analysis (DEA) is most widely used (see the following paragraphs) [10]. DEA is a nonparametric mathematical method to measure the efficiency of decision-making units (DMUs) $[11,12]$. DEA has been applied to evaluate the performance of hospitals, supply chains, universities, and other entities [13]. The CCR model (proposed by Charnes et al.) and the BCC model (proposed by Banker et al.) are two basic DEA models $[14,15]$. The former assumes that technology exhibits constant returns to scale (CRS), and the latter is developed under the condition of variable returns to scale (VRS). In the past forty years, many DEA models, e.g., integer-valued DEA models [16], super-efficiency DEA models [17], generalized DEA models [18], slack-based DEA models [19], network DEA models [20], and stochastic DEA models [21], have been proposed based on the two models.

Scholars have been studying the energy efficiency measurement for a long time. Ramanathan applied the CCR model and the BCC model to evaluate the energy efficiency of railways and roadways in India [22]. Hu and Wang used the DEA method to measure the total-factor energy efficiency of 29 regions in China [23]. Wu et al. proposed a DEA technique with nonhomogeneous variables to estimate the energy efficiency of industrial sectors in China [24]. Geng et al. proposed a DEA approach with the affinity propagation clustering algorithm (AP-DEA) to evaluate the energy efficiency of petrochemical industries [25]. However, undesirable outputs, e.g., carbon emissions, are not considered in the aforementioned DEA models. These energy efficiency evaluation models are not suitable in reality because the fossil fuel energy consumption will definitely generate carbon emissions [26]. Therefore, the efficiency scores obtained from these models may be distorted.

Zhou et al. proposed slacks-based measures (SBM) to evaluate the $\mathrm{CO}_{2}$ emission efficiency of 30 OECD countries (the Organization for Economic Cooperation and Development) [27]. Zhou et al. applied DEA approaches to evaluate the carbon emission efficiency of eight world regions [28]. Wang et al. developed DEA approaches to compare the environmental efficiency of several provinces in China by taking $\mathrm{CO}_{2}$ emissions into account [29]. Wei et al. evaluated the $\mathrm{CO}_{2}$ emission efficiency of China's 29 provinces by an extended SBMDEA model [30]. Wang et al. applied a DEA window analysis approach to evaluate the regional environmental efficiency in China considering $\mathrm{CO}_{2}$ emissions [31]. Guo et al. developed a dynamic DEA model to measure the energy efficiency of OECD countries by taking $\mathrm{CO}_{2}$ emissions into consideration [32]. Cheng et al. used a time substitution DEA approach to estimate the carbon emission efficiency of China [33]. Chu et al. proposed an SBM-DEA approach to evaluate the environmental efficiency of China's transportation system considering $\mathrm{CO}_{2}$ emissions [34]. Cui developed a network DEA approach to measure the greenhouse gas emission efficiency of 28 international airlines [35]. Djordjevic and Krmac applied a nonradial DEA and TOPSIS (the Technique for Order of Preference by Similarity to Ideal Solution) approach to measure the environmental efficiency of European transport systems by taking greenhouse gas emissions into account [36]. Zhou et al. proposed a DEA method according to an exponential transformation to evaluate the energy efficiency of China's industry considering greenhouse gas emissions [37]. Omrani et al. developed a DEA-cooperative game method to estimate the energy efficiency of the transportation system in Iran by taking greenhouse gas emissions into account [38]. The disadvantage of the abovementioned literature is that they assume deterministic carbon emissions. However, it is impossible to get precise data related to carbon emissions, which could be caused by measurement errors, natural uncertainty of carbon emissions, and so on [39]. The results would be erroneous if decision-makers do not consider the uncertainty of carbon emissions when measuring the ECEE [39-43]. As a matter of fact, the deterministic DEA model is only a particular case of the uncertain DEA model [39].

Wu et al. [40], Jin et al. [41], Zha et al. [39], Chen et al. [42], and Zhou et al. [43] used the chance-constrained DEA method to evaluate the environmental efficiency considering uncertain undesirable outputs. However, as far as we know, there is no literature on measuring the efficiency of regional transportation systems (RTS) by taking the uncertainty of carbon emissions into account, especially China's RTS. It is necessary to research the RTS because of the unbalanced regional development in China [44]. The Chinese government should set up different policies for different RTS to improve their ECEE.

The innovation of this paper is that, to the best of our knowledge, this is the first paper to measure the efficiency of RTS by taking uncertain carbon emissions into consideration. The contributions of this paper are that (1) a radial chance-constrained DEA model is presented to evaluate the overall efficiency; (2) a nonradial chanceconstrained DEA model is developed to accurately estimate the pure energy efficiency (PEE) and the pure carbon emission efficiency (PCEE); (3) the proposed approaches are applied in the RTS in China and some valuable suggestions are provided.

This paper is structured as follows. The chance-constrained DEA models are developed by taking uncertain carbon emissions into consideration in Section 2. In Section 3 , these models are applied to estimate the ECEE of thirty RTS in China, and some valuable suggestions are provided. Some conclusions are proposed in Section 4.

\section{Methodology}

A regional transportation system can be regarded as a DMU. Suppose that $\mathrm{DMU}_{i}(i \in 1,2, \ldots, q)$ has $p$ nonenergy inputs $x_{j i}(j=1,2, \ldots, p), r$ energy inputs $e_{t i}(t=1,2, \ldots, r), m$ desirable outputs $y_{l i}(l=1,2, \ldots, m)$, and an undesirable output $c_{i}$ (carbon emissions). 
To measure the environmental efficiency, Färe et al. handled undesirable outputs under the assumption of the weak disposability of undesirable outputs [45]. Nowadays, this method has been widely used. For given levels of inputs, it is impossible to simultaneously reduce carbon emissions and expand desirable outputs, e.g., passenger turnover, freight turnover, and transportation value-added. Therefore, to estimate the overall efficiency of RTS, we propose a radial DEA model (model 1) under the assumption of the weak disposability of the undesirable output (the amount of carbon emissions) [45, 46]. Model (1) is a radial DEA model as this model aims to proportionally reduce inputs and the undesirable output of $\mathrm{DMU}_{k}[22,45]$.

$$
\begin{aligned}
\Psi_{k}^{D}= & \min \left(\theta_{k}-\varepsilon\left(\sum_{l=1}^{m} s_{l}^{y+}+\sum_{j=1}^{p} s_{j}^{x-}+\sum_{t=1}^{r} s_{t}^{e-}\right)\right), \\
\text { s.t. } & \sum_{i=1}^{q} \lambda_{i} y_{l i}-s_{l}^{y+}=y_{l k}, \quad l=1,2, \ldots, m, \\
& \sum_{i=1}^{q} \lambda_{i} c_{i}=\theta_{k} c_{k}, \\
& \sum_{i=1}^{q} \lambda_{i} x_{j i}+s_{j}^{x-}=\theta_{k} x_{j k}, \quad j=1,2, \ldots, p, \\
& \sum_{i=1}^{q} \lambda_{i} e_{t i}+s_{t}^{e-}=\theta_{k} e_{t k}, \quad t=1,2, \ldots, r, \\
& \delta \sum_{i=1}^{q} \lambda_{i}=\delta, \\
& \lambda_{i} \geq 0, \quad i=1,2, \ldots, q, \\
& s_{l}^{y+} \geq 0, \quad l=1,2, \ldots, m, \\
& s_{j}^{x-} \geq 0, \quad j=1,2, \ldots, p \\
& s_{t}^{e-} \geq 0, \quad t=1,2, \ldots, r,
\end{aligned}
$$

where $\lambda_{i}$ is the weight of $\mathrm{DMU}_{i} ; \varepsilon$ is a non-Archimedean infinitesimal; and $s_{j}^{x-}, s_{t}^{e-}$, and $s_{l}^{y+}$ are the slack variables for the $j$ th nonenergy input, the $t$ th energy input, and the $l$ th desirable output, respectively; $\delta=0$ and $\delta=1$ respectively represent the assumption of CRS and VRS.

The optimal value $\Psi_{k}^{D *}$ is the technical efficiency score (or pure technical efficiency score) of $\mathrm{DMU}_{k} a$ when $\delta=0$ (or $\delta=1$ ). According to the definition of DEA efficiency, we have the following propositions: (i) $\mathrm{DMU}_{k}$ is efficient when $\Psi_{k}^{D *}=1\left(\theta_{k}^{*}=1\right.$ and $\left.s_{j}^{x-*}=s_{l}^{y+*}=s_{t}^{e-*}=0\right)$; (ii) $D M U_{k}$ is inefficient when $\Psi_{k}^{D *}<1$.

Model (1) is called the radial deterministic DEA model because it can only be used when all the needed data are precise. However, as discussed above, the value of carbon emissions is uncertain. Therefore, we have to develop a stochastic DEA model. To do so, we first propose model (2) that is the dual of model (1). All slack variables are deleted in the following transformation processes for the sake of clarity.

$$
\begin{aligned}
& \Psi_{k}^{D}=\max \left(\sum_{l=1}^{m} \mu_{l} y_{l k}-\delta \mu_{0}\right), \\
& \text { s.t. } \quad \sum_{l=1}^{m} \mu_{l} y_{l i}-\delta \mu_{0}-\sum_{j=1}^{p} v_{j} x_{j i}-\sum_{t=1}^{r} f_{t} e_{t i}, \\
& \quad-w c_{i} \leq 0, \quad i=1,2, \ldots, q \\
& \sum_{j=1}^{p} v_{j} x_{j k}+\sum_{t=1}^{r} f_{t} e_{t k}+w c_{k}=1, \\
& \mu_{l} \geq 0, \quad l=1,2, \ldots, m, \\
& v_{j} \geq 0, \quad j=1,2, \ldots, p, \\
& f_{t} \geq 0, \quad t=1,2, \ldots, r, \\
& w \text { and } \mu_{0} \text { are free, }
\end{aligned}
$$

where $\mu_{l}, v_{j}, f_{t}$, and $w$ are the weights for the $l$ th desirable output, the $j$ th nonenergy input, the $t$ th energy input, and the undesirable out, respectively.

As stated in Section 1, the stochastic chance-constrained DEA is an effective method to evaluate the environmental efficiency considering uncertain undesirable outputs. Thus, we also propose a radial stochastic chance-constrained DEA model (model 3) based on model (2) to measure the overall efficiency of RTS by taking uncertain carbon emissions into consideration.

$$
\begin{aligned}
& \Psi_{k}^{S}=\max \left(\sum_{l=1}^{m} \mu_{l} y_{l k}-\delta \mu_{0}\right), \\
& \text { s.t. } \quad P\left\{\sum_{l=1}^{m} \mu_{l} y_{l i}-\delta \mu_{0}-\sum_{j=1}^{p} v_{j} x_{j i}-\sum_{t=1}^{r} f_{t} e_{t i}-w \hat{c}_{i} \leq 0\right\} \\
& \quad \geq 1-\alpha_{i}, \quad i=1,2, \ldots, q, \\
& \sum_{j=1}^{p} v_{j} x_{j k}+\sum_{t=1}^{r} f_{t} e_{t k}+w E\left(\hat{c}_{k}\right)=1, \\
& \mu_{l} \geq 0, \quad l=1,2, \ldots, m, \\
& v_{j} \geq 0, \quad j=1,2, \ldots, p, \\
& f_{t} \geq 0, \quad t=1,2, \ldots, r,
\end{aligned}
$$

$w$ and $\mu_{0}$ are free,

where $\hat{c_{i}}$ indicates stochastic carbon emissions; $E\left(\hat{c_{k}}\right)$ represents the expected value of $\hat{c_{k}} ; P$ is the "probability" measurement of the corresponding constraint; and $1-\alpha_{i}$ is the probability of satisfying the inequality $\sum_{l=1}^{m} \mu_{l} y_{l i}-\delta \mu_{0}-\sum_{j=1}^{p} v_{j} x_{j i}-\sum_{t=1}^{r} f_{t} e_{t i}-w c_{i} \leq 0$. In other words, $1-\alpha_{i}$ indicates a confidence level while $\alpha_{i}$ represents a risk criterion $[47,48]$.

As model (3) is a nonlinear model, we should transform it into a linear model. Obviously, inequality (4) is only a transformation of the stochastic chance constraint in model (3). 


$$
P\left\{\sum_{l=1}^{m} \mu_{l} y_{l i}-\delta \mu_{0}-\sum_{j=1}^{p} v_{j} x_{j i}-\sum_{t=1}^{r} f_{t} e_{t i} \leq w \hat{c}_{i}\right\} \geq 1-\alpha_{i} .
$$

Let us define that $\overline{c_{i}}$ denotes the expected value of $\hat{c_{i}}$ and $G_{i}$ indicates the variance of $w c_{i}$. The inequality (4) then can be transformed into the following inequality:

(4)

$$
P\left\{\frac{\sum_{l=1}^{m} \mu_{l} y_{l i}-\delta \mu_{0}-\sum_{j=1}^{p} v_{j} x_{j i}-\sum_{t=1}^{r} f_{t} e_{t i}-w \overline{c_{i}}}{\sqrt{G_{i}}} \leq \frac{w \hat{c}_{i}-w \overline{c_{i}}}{\sqrt{G_{i}}}\right\} \geq 1-\alpha_{i} .
$$

Assume that $\left(w \hat{c_{i}}-w \overline{c_{i}}\right) / \sqrt{G_{i}}$ obeys $N(0,1)$ (standard normal distribution) and $\Phi$ denotes its cumulative distribution function. The inequality (5) then can be transformed into the following inequality:

$$
\frac{\sum_{l=1}^{m} \mu_{l} y_{l i}-\delta \mu_{0}-\sum_{j=1}^{p} v_{j} x_{j i}-\sum_{t=1}^{r} f_{t} e_{t i}-w \overline{c_{i}}}{\sqrt{G_{i}}} \leq \Phi^{-1}\left(\alpha_{i}\right),
$$

where $\Phi^{-1}$ represents the inverse function of $\Phi$. We assume $\hat{c}_{i}=\overline{c_{i}}+\varphi_{i} \kappa_{i}$ and $E\left(\hat{c_{i}}\right)=\overline{c_{i}}$, where $\overline{c_{i}}$ represents $\hat{c}_{i}$ 's expected value and $\varphi_{i}$ denotes the standard deviation. Assume that $\kappa_{i}=\left(w \hat{c}_{i}-w \overline{c_{i}}\right) / \sqrt{G_{i}}$ follows $N(0,1)$. Then, we have $G_{i}=\left(w \varphi_{i}\right)^{2}$, and model (3) can be transformed into the following model:

$$
\begin{aligned}
& \Psi_{k}^{S}=\max \left(\sum_{l=1}^{m} \mu_{l} y_{l k}-\delta \mu_{0}\right), \\
& \text { s.t. } \quad \sum_{l=1}^{m} \mu_{l} y_{l i}-\delta \mu_{0}-\sum_{j=1}^{p} v_{j} x_{j i}-\sum_{t=1}^{r} f_{t} e_{t i} \\
& \quad-w\left(\overline{c_{i}}+\Phi^{-1}\left(\alpha_{i}\right) \varphi_{i}\right) \leq 0, \quad i=1,2, \ldots, q, \\
& \sum_{j=1}^{p} v_{j} x_{j k}+\sum_{t=1}^{r} f_{t} e_{t k}+w \overline{c_{k}}=1, \\
& \mu_{l} \geq 0, \quad l=1,2, \ldots, m, \\
& v_{j} \geq 0, \quad j=1,2, \ldots, p, \\
& f_{t} \geq 0, \quad t=1,2, \ldots, r, \\
& w \text { and } \mu_{0} \text { are free. }
\end{aligned}
$$

The dual of model (7) can be denoted by model (8) that aims to proportionally reduce inputs and uncertain carbon emissions of $\mathrm{DMU}_{k}$. It is worth noting that slack variables are added into model (8). We have transformed nonlinear model (3) into linear model (8) that is called the radial chance-constrained DEA model. The optimal objective function value $\left(\Psi_{k}^{S *}\right)$ of model (8) is the technical efficiency score (or pure technical efficiency score) of $\mathrm{DMU}_{k}$ when $\delta=0$ (or $\delta=1$ ).

$$
\begin{aligned}
\Psi_{k}^{S}= & \min \left(\theta_{k}-\varepsilon\left(\sum_{l=1}^{m} s_{l}^{y+}+\sum_{j=1}^{p} s_{j}^{x-}+\sum_{t=1}^{r} s_{t}^{e-}\right)\right), \\
\text { s.t. } \quad & \sum_{i=1}^{q} \lambda_{i} y_{l i}-s_{l}^{y+}=y_{l k}, \quad l=1,2, \ldots, m, \\
& \sum_{i=1}^{q} \lambda_{i}\left(\overline{c_{i}}+\Phi^{-1}\left(\alpha_{i}\right) \varphi_{i}\right)=\theta_{k} \overline{c_{k}}, \\
& \sum_{i=1}^{q} \lambda_{i} x_{j i}+s_{j}^{x-}=\theta_{k} x_{j k}, \quad j=1,2, \ldots, p \\
& \sum_{i=1}^{q} \lambda_{i} e_{t i}+s_{t}^{e-}=\theta_{k} e_{t k}, \quad t=1,2, \ldots, r, \\
& \delta \sum_{i=1}^{q} \lambda_{i}=\delta \\
& \lambda_{i} \geq 0, \quad i=1,2, \ldots, q \\
& s_{l}^{y+} \geq 0, \quad l=1,2, \ldots, m, \\
& s_{j}^{x-} \geq 0, \quad j=1,2, \ldots, p \\
& s_{t}^{e-} \geq 0, \quad t=1,2, \ldots, r .
\end{aligned}
$$

According to the definition of DEA efficiency, we have the following propositions: (i) $\mathrm{DMU}_{k}$ is superefficient when $\Psi_{k}^{S *}>1$; (ii) $\mathrm{DMU}_{k}$ is efficient when $\Psi_{k}^{S *}=1\left(\theta_{k}^{*}=1\right.$ and $s_{j}^{x-*}=s_{l}^{y+*}=s_{t}^{e-*}=0$ ); (iii) $\mathrm{DMU}_{k}$ is inefficient when $\Psi_{k}^{S *}<1$.

The advantages of the radial chance-constrained DEA model are that (1) it can be used to deal with undesirable outputs that cannot be disposed of; (2) it can be used to handle stochastic variables. However, model (8) cannot be used to evaluate the PEE or PCEE. Therefore, we have to extend it to a nonradial chance-constrained DEA model (model 9). Model (9) optimizes the carbon emissions and energy consumption without changing the desirable outputs and nonenergy inputs. We evaluate the ECEE by assigning weights to the PEE and PCEE $[29,39]$. 


$$
\begin{aligned}
\Psi_{k}^{\mathrm{ES}}= & \min \left(\omega_{e} \sum_{t=1}^{r} \rho_{t} \theta_{t}^{e}+\varpi_{c} \theta^{c}-\varepsilon\left(\sum_{l=1}^{m} s_{l}^{y+}+\sum_{j=1}^{p} s_{j}^{x-}+\sum_{t=1}^{r} s_{t}^{e-}\right)\right) \\
\text { s.t. } \quad & \sum_{i=1}^{q} \lambda_{i} y_{l i}-s_{l}^{y+}=y_{l k}, \quad l=1,2, \ldots, m, \\
& \sum_{i=1}^{q} \lambda_{i}\left(\overline{c_{i}}+\varphi_{i} \Phi^{-}\left(\alpha_{i}\right)\right)=\theta^{c} \overline{c_{k}} \\
& \sum_{i=1}^{q} \lambda_{i} x_{j i}+s_{j}^{x-}=x_{j k}, \quad j=1,2, \ldots, p \\
& \sum_{i=1}^{q} \lambda_{i} e_{t i}+s_{t}^{e-}=\theta_{t}^{e} e_{t k}, \quad t=1,2, \ldots, r \\
& \delta \sum_{i=1}^{q} \lambda_{i}=\delta, \\
& \lambda_{i} \geq 0, \quad i=1,2, \ldots, q \\
& s_{l}^{y+} \geq 0, \quad l=1,2, \ldots, m \\
& s_{j}^{x-} \geq 0, \quad j=1,2, \ldots, p \\
& s_{t}^{e-} \geq 0, \quad t=1,2, \ldots, r
\end{aligned}
$$

where $\theta_{t}^{e}$ indicates the $t$ th PEE (pure efficiency of energy $t$ ); $\theta^{c}$ is the PCEE; $\omega_{e}$ and $\omega_{c}$ respectively represent the weights of the PEE and PCEE; and $\rho_{t}$ is the weight of the $t$ th energy input. There must be $\Phi_{e}+\varpi_{c}=1$ and $\sum_{t=1}^{r} \rho_{t}=1$. The PEE indicates the utilization performance of transportation fuels, and the PCEE reflects the performance of carbon emission cuts.

For an inefficient regional transportation system, its potential energy savings and carbon emission cuts can be calculated using the following equations, respectively:

$$
\begin{aligned}
\Delta e_{t k} & =\left(1-\theta_{t}^{e *}\right) e_{t k}+s_{t}^{e-*}, \\
\Delta \overline{c_{k}} & =\left(1-\theta^{c *}\right) \overline{c_{k}} .
\end{aligned}
$$

\section{Empirical Study}

The proposed models are used to estimate the ECEE of China's RTS in 2017.

3.1. Data. Mainland China includes 31 provinces, and the regional disparity is wide. These provinces can be classified into three areas, i.e., the eastern area, the central area, and the western area. The eastern area, which is the most developed and densely populated area, comprises of eleven provinces; The central area includes ten provinces; The western area, which is the least developed and sparsely populated area, is composed of ten provinces [44]. The data about transportation energy consumption in Tibet are not available so that we have to exclude Tibet. Therefore, thirty provinces are involved in this research.

We select employed persons (labor), fixed-asset investment (capital), and civil motor vehicles as three nonenergy input variables. Gasoline consumption, kerosene consumption, and diesel consumption are regarded as three energy input variables. Passenger turnover, freight turnover, and transportation value-added are selected as three desirable output variables. The amount of carbon emissions from transportation is defined as a single undesirable output.

The chosen nonenergy input, desirable outputs, and undesirable outputs in this paper are vital indicators for transport systems and have been used widely in previous research $[36,38]$. Gasoline, kerosene, and diesel are selected as three energy inputs because they are the dominant transportation fuels in China. As shown in Figure 1, diesel makes up more than $40 \%$ of the total transportation energy consumption, gasoline occupies more than $20 \%$, and kerosene accounts for more than 10\% [49]. We cannot select all transportation fuels as energy inputs according to the rule of thumb [50].

The data related to employed persons (unit: 10 thousand persons), civil motor vehicles (unit: 10 thousand vehicles), fixed-asset investment (unit: 1 billion $\mathrm{CNY}$ ), passenger turnover (unit: 1 billion passenger $/ \mathrm{km}$ ), freight turnover (unit: 1 billion ton $/ \mathrm{km}$ ), and transportation value-added (unit: 1 billion CNY) are obtained from [51]. The data related to energy consumption (unit: 10 thousand tons of standard coal equivalent) are calculated using the following equation:

$$
e_{t i}=z_{t i} \times F_{t}, \quad t=1,2,3,
$$

where $e_{t i}$ (unit: 10 thousand tons of standard coal equivalent) represents the consumption of energy $t$ by $\mathrm{DMU}_{i} ; z_{t i}$ (unit: 10 thousand tons) also indicates the consumption of energy $t$ by $\mathrm{DMU}_{i}$; and $F_{t}$ denotes the standard coal coefficient of the $t$ th energy (gasoline, 1.4714; kerosene, 1.4714; diesel, 1.4571) [52]. The values of $z_{t i}(t=1,2,3)$ are obtained from [49].

The amount of carbon emissions from transportation (units: 10 thousand tons) can be calculated using the following equation:

$$
c_{i}=\sum_{t=1}^{6}\left(e_{t i} \times D_{t}\right) \text {, }
$$

where $c_{i}$ represents the carbon emissions of $\mathrm{DMU}_{i} ; e_{t i}$ indicates the consumption of the $t$ th energy by $\mathrm{DMU}_{i}$; and $D_{t}$ denotes the carbon emission coefficient for the $t$ th energy (gasoline, 0.5538; kerosene, 0.5714; diesel, 0.5921; coal, 0.7559; fuel oil, 0.6185; natural gas, 0.4483) [53]. Although we only select three transportation fuels as energy inputs, we want to calculate carbon emissions generated from all transportation fuels. Note that the electric power, which can be generated by wind power and hydropower, is not included in our research because the carbon emission coefficients of both wind power and hydropower are zero.

We suppose that the expected carbon emissions from transportation are equal to the estimated carbon emissions. Therefore, we have $E\left(\hat{c}_{i}\right)=\overline{c_{i}}=\hat{c}_{i}(i=1,2, \ldots, q)$. The standard deviation of carbon emissions from transportation is calculated using the dataset of the estimated carbon emissions from 2013 to 2017. The descriptive statistics of all selected variables of RTS in mainland China are shown in Table 1. Table 2 shows the detailed data related to carbon emissions from transportation. 


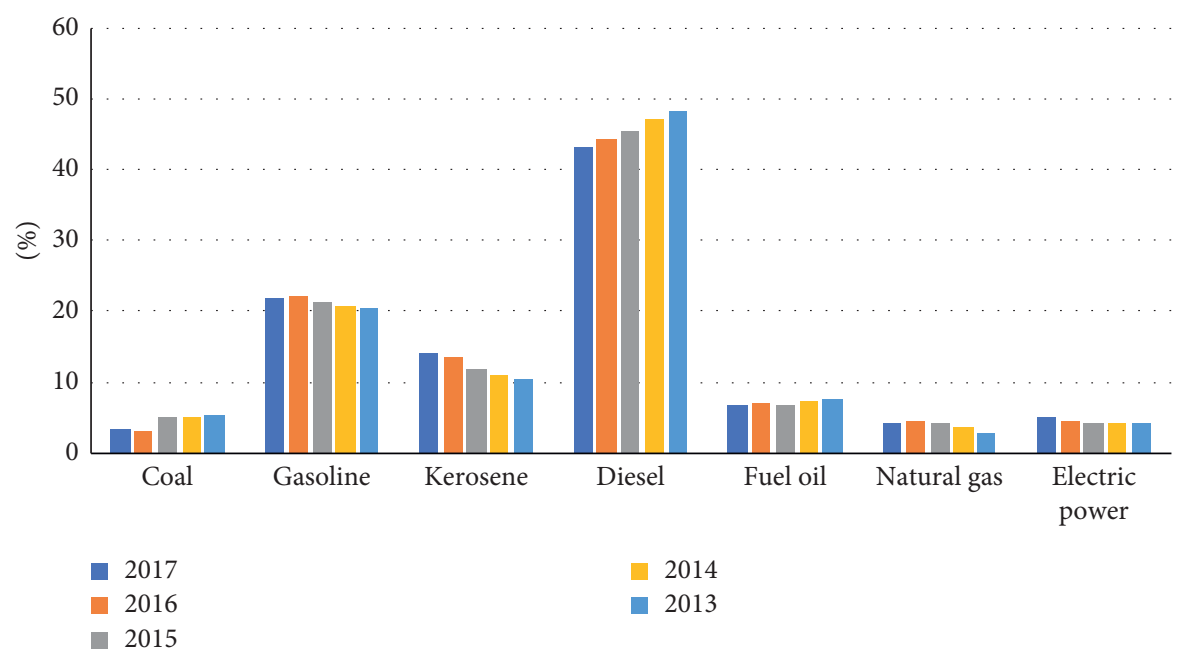

Figure 1: China's transportation energy consumption.

TABle 1: Descriptive statistics of all selected variables.

\begin{tabular}{lcccc}
\hline Variable & Max & Min & Mean & Std. dev. \\
\hline Employed persons & 52.05 & 3.23 & 22.11 & 12.00 \\
Fixed-asset investment & 449.26 & 33.01 & 188.70 & 114.44 \\
Civil motor vehicles & 1922.38 & 98.73 & 688.92 & 494.96 \\
Gasoline & 853.54 & 12.09 & 264.67 & 216.21 \\
Kerosene & 958.79 & 0.00 & 170.73 & 233.92 \\
Diesel & 1618.71 & 61.74 & 520.02 & 351.02 \\
Passenger turnover & 201.23 & 9.92 & 77.52 & 50.59 \\
Freight turnover & 2791.98 & 51.95 & 632.24 & 651.67 \\
Added-value & 358.09 & 10.37 & 133.48 & 89.72 \\
Carbon emissions & 1848.20 & 101.50 & 659.15 & 386.65 \\
\hline
\end{tabular}

\subsection{Results}

3.2.1. Overall Efficiency. The overall efficiency of the thirty RTS in mainland China is calculated using the proposed radial chance-constrained DEA model (model 8). We also compare the efficiency scores resulting from model (8) with those resulting from the radial deterministic DEA model (model 1).

Tables 3 and 4 respectively show the efficiency scores under the assumption of CRS $(\delta=0)$ and VRS $(\delta=1)$. We use four groups of values $\left(\alpha_{i}=0.5, \alpha_{i}=0.1, \alpha_{i}=0.05\right.$, and $\left.\alpha_{i}=0.01\right)$ to study the effects of $\alpha_{i}$ on the results of efficiency evaluation, and we select $\alpha_{i}=0.05$ as the risk criterion in this study as it is set 0.05 in the related literature [39-43].

As shown in Table 3, the efficiency scores resulting from model (1) are the same as those resulting from model (8) with $\alpha_{i}=0.5$, which implies that the radial deterministic DEA model (model 1) is only a particular case of the radial chance-constrained DEA model (model 8). Furthermore, only four RTS are regarded as inefficient DMUs based on their overall technical efficiency scores resulting from model (1). However, based on their overall technical efficiency scores resulting from model (8), we have thirteen inefficient RTS when $\alpha_{i}=0.1, \alpha_{i}=0.05$, or $\alpha_{i}=0.01$. The results prove that decision-makers should take the uncertainty of carbon emissions into account when they measure the efficiency of
TABle 2: Carbon emissions.

\begin{tabular}{lccc}
\hline Area & Province & Mean & Std. dev. \\
\hline \multirow{4}{*}{ East } & Beijing & 622.92 & 38.24 \\
& Tianjin & 233.78 & 5.39 \\
& Hebei & 487.88 & 31.90 \\
& Liaoning & 1008.50 & 61.30 \\
& Shanghai & 1241.82 & 142.31 \\
& Jiangsu & 1077.54 & 72.99 \\
& Zhejiang & 793.02 & 33.80 \\
& Fujian & 560.66 & 48.75 \\
& Shandong & 1082.88 & 76.60 \\
& Guangdong & 1668.08 & 140.85 \\
& Hainan & 162.14 & 4.35 \\
\hline \multirow{4}{*}{ Central } & Shanxi & 517.54 & 27.50 \\
& Nei Mongol & 632.02 & 111.62 \\
& Jilin & 464.58 & 40.56 \\
& Heilongjiang & 614.18 & 23.60 \\
Anhui & 555.98 & 31.15 \\
& Jiangxi & 378.08 & 22.92 \\
& Henan & 696.00 & 32.46 \\
& Hubei & 865.16 & 108.76 \\
& Hunan & 739.22 & 80.20 \\
& Guangxi & 486.14 & 58.30 \\
\hline Chongqing & 491.32 & 51.57 \\
& Sichuan & 594.00 & 159.15 \\
Guizhou & 393.00 & 29.62 \\
& Yunnan & 566.96 & 34.73 \\
& Shaanxi & 394.06 & 27.25 \\
& Gansu & 276.88 & 8.04 \\
& Qinghai & 89.10 & 13.91 \\
& Ningxia & 100.90 & 3.31 \\
& Xinjiang & 501.36 & 64.89 \\
\hline & & & \\
& & & \\
& & &
\end{tabular}

RTS. Otherwise, the results may be doubtful. As shown in Table 4 , we can get the same results under the assumption of $\operatorname{VRS}(\delta=1)$.

The proposed radial chance-constrained DEA model (model 8) is more effective than the radial deterministic DEA model (model 1) because (i) it has higher discriminatory ability than model (1) as stated above; (ii) we cannot 
Table 3: Overall technical efficiency (assuming CRS).

\begin{tabular}{|c|c|c|c|c|c|c|}
\hline \multirow{2}{*}{ Area } & \multirow{2}{*}{ Province } & \multirow{2}{*}{ Model 1} & \multicolumn{4}{|c|}{ Model 8} \\
\hline & & & $\alpha_{i}=0.5$ & $\alpha_{i}=0.1$ & $\alpha_{i}=0.05$ & $\alpha_{i}=0.01$ \\
\hline \multirow{11}{*}{ East } & Beijing & 1.000 & 1.000 & 0.977 & 0.971 & 0.961 \\
\hline & Tianjin & 1.000 & 1.000 & 1.029 & 1.037 & 1.053 \\
\hline & Hebei & 1.000 & 1.000 & 1.085 & 1.109 & 1.154 \\
\hline & Liaoning & 1.000 & 1.000 & 1.056 & 1.072 & 1.101 \\
\hline & Shanghai & 1.000 & 1.000 & 1.120 & 1.154 & 1.216 \\
\hline & Jiangsu & 1.000 & 1.000 & 0.919 & 0.905 & 0.886 \\
\hline & Zhejiang & 1.000 & 1.000 & 1.002 & 1.003 & 1.004 \\
\hline & Fujian & 0.992 & 0.992 & 0.906 & 0.892 & 0.875 \\
\hline & Shandong & 1.000 & 1.000 & 1.033 & 1.042 & 1.058 \\
\hline & Guangdong & 1.000 & 1.000 & 0.948 & 0.937 & 0.918 \\
\hline & Hainan & 1.000 & 1.000 & 0.995 & 0.994 & 0.991 \\
\hline \multirow{10}{*}{ Central } & Shanxi & 1.000 & 1.000 & 1.011 & 1.013 & 1.018 \\
\hline & Nei Mongol & 1.000 & 1.000 & 0.974 & 0.969 & 0.963 \\
\hline & Jilin & 1.000 & 1.000 & 0.975 & 0.969 & 0.959 \\
\hline & Heilongjiang & 1.000 & 1.000 & 1.021 & 1.027 & 1.038 \\
\hline & Anhui & 1.000 & 1.000 & 1.047 & 1.060 & 1.085 \\
\hline & Jiangxi & 1.000 & 1.000 & 1.071 & 1.092 & 1.130 \\
\hline & Henan & 1.000 & 1.000 & 1.051 & 1.066 & 1.097 \\
\hline & Hubei & 1.000 & 1.000 & 0.965 & 0.958 & 0.947 \\
\hline & Hunan & 1.000 & 1.000 & 1.060 & 1.075 & 1.101 \\
\hline & Guangxi & 0.857 & 0.857 & 0.843 & 0.846 & 0.857 \\
\hline \multirow{9}{*}{ West } & Chongqing & 1.000 & 1.000 & 0.927 & 0.912 & 0.890 \\
\hline & Sichuan & 0.808 & 0.808 & 0.819 & 0.822 & 0.827 \\
\hline & Guizhou & 1.000 & 1.000 & 1.043 & 1.054 & 1.073 \\
\hline & Yunnan & 0.435 & 0.435 & 0.421 & 0.426 & 0.436 \\
\hline & Shaanxi & 1.000 & 1.000 & 1.020 & 1.024 & 1.031 \\
\hline & Gansu & 1.000 & 1.000 & 1.031 & 1.041 & 1.061 \\
\hline & Qinghai & 1.000 & 1.000 & 1.155 & 1.198 & 1.278 \\
\hline & Ningxia & 1.000 & 1.000 & 1.042 & 1.054 & 1.076 \\
\hline & Xinjiang & 1.000 & 1.000 & 0.948 & 0.937 & 0.919 \\
\hline Average & & 0.970 & 0.970 & 0.983 & 0.989 & 1.000 \\
\hline
\end{tabular}

rank efficient RTS because all of their efficiency scores obtained from model (1) are equal to one (for example, as shown in Table 3, Beijing, Tianjin, Hebei, Liaoning, Shanghai, Jiangsu, Zhejiang, Shandong, Guangdong, Hainan, Shanxi, Nei Mongol, Jilin, Heilongjiang, Anhui, Jiangxi, Henan, Hubei, Hunan, Chongqing, Guizhou, Shaanxi, Gansu, Qinghai, Ningxia, and Xinjiang.), but their efficiency scores resulting from the radial chance-constrained DEA model can be greater than one, which makes it possible to differentiate the efficient RTS.

As shown in Tables 3 and 4, the efficiency scores (technical efficiency score and pure technical efficiency score) of Qinghai are the highest, while Yunnan has the lowest scores. Therefore, Yunnan should make every effort to improve the performance of its transportation system.

As shown in Table 5, based on the overall efficiency scores of the three areas under both CRS and VRS, the performance of east China is the best while west China is the worst. It indicates that the unbalanced regional development of overall efficiency in transportation corresponds with the unbalanced regional economic development.

3.2.2. $P E E$ and PCEE. The proposed nonradial chanceconstrained DEA model (model 9) is used to evaluate the
PEE and PCEE of China's RTS. We set $\omega_{e}=\omega_{c}=0.5$ because carbon emissions are generated by combusting energy fuels. Moreover, the weights for the three energy inputs can be calculated using the following equation [39]:

$$
\rho_{t}=\frac{D_{t}}{\sum_{t=1}^{3} D_{t}}
$$

where $D_{t}$ is the carbon emission coefficient of energy $t$ (as shown in Section 3.1). We finally obtain $\rho_{\text {kerosene }}=0.332732$, $\rho_{\text {kerosene }}=0.332732$, and $\rho_{\text {diesel }}=0.344785$.

Tables 6 and 7 show the efficiency scores of these RTS resulting from the nonradial chance-constrained DEA model (model 9) under the assumption of CRS $(\delta=0)$ and VRS $(\delta=1)$, respectively. It can be observed that the transportation system of Ningxia does not have feasible solutions for its kerosene utilization efficiency. The reason is that the consumption of kerosene in Ningxia's transportation system is zero.

Table 6 shows that the technical efficiency score $\left(\Psi_{k}^{\mathrm{ES}}\right)$ of energy utilization and carbon emissions in Qinghai is the highest while Yunnan has the lowest score. The results are consistent with those obtained from model (8) under the CRS condition. The technical efficiency score $\left(\Psi_{k}^{\mathrm{Gas}}\right)$ of gasoline utilization in Henan is the highest while Heilongjiang has the lowest score. The technical efficiency score 
TABLE 4: Overall pure technical efficiency (assuming VRS).

\begin{tabular}{|c|c|c|c|c|c|c|}
\hline \multirow{2}{*}{ Area } & \multirow{2}{*}{ Province } & \multirow{2}{*}{ Model 1} & \multicolumn{4}{|c|}{ Model 8} \\
\hline & & & $\alpha_{i}=0.5$ & $\alpha_{i}=0.1$ & $\alpha_{i}=0.05$ & $\alpha_{i}=0.01$ \\
\hline \multirow{11}{*}{ East } & Beijing & 1.000 & 1.000 & 0.977 & 0.972 & 0.962 \\
\hline & Tianjin & 1.000 & 1.000 & 1.029 & 1.037 & 1.053 \\
\hline & Hebei & 1.000 & 1.000 & 1.085 & 1.109 & 1.154 \\
\hline & Liaoning & 1.000 & 1.000 & 1.057 & 1.073 & 1.102 \\
\hline & Shanghai & 1.000 & 1.000 & 1.129 & 1.165 & 1.234 \\
\hline & Jiangsu & 1.000 & 1.000 & 1.080 & 1.102 & 1.144 \\
\hline & Zhejiang & 1.000 & 1.000 & 1.006 & 1.007 & 1.010 \\
\hline & Fujian & 0.996 & 0.996 & 0.910 & 0.897 & 0.876 \\
\hline & Shandong & 1.000 & 1.000 & 1.080 & 1.103 & 1.145 \\
\hline & Guangdong & 1.000 & 1.000 & 1.097 & 1.125 & 1.176 \\
\hline & Hainan & 1.000 & 1.000 & 1.027 & 1.035 & 1.049 \\
\hline \multirow{10}{*}{ Central } & Shanxi & 1.000 & 1.000 & 1.019 & 1.025 & 1.034 \\
\hline & Nei Mongol & 1.000 & 1.000 & 1.040 & 1.047 & 1.058 \\
\hline & Jilin & 1.000 & 1.000 & 0.975 & 0.969 & 0.960 \\
\hline & Heilongjiang & 1.000 & 1.000 & 1.024 & 1.031 & 1.043 \\
\hline & Anhui & 1.000 & 1.000 & 1.048 & 1.061 & 1.086 \\
\hline & Jiangxi & 1.000 & 1.000 & 1.072 & 1.092 & 1.130 \\
\hline & Henan & 1.000 & 1.000 & 1.058 & 1.074 & 1.105 \\
\hline & Hubei & 1.000 & 1.000 & 0.969 & 0.963 & 0.960 \\
\hline & Hunan & 1.000 & 1.000 & 1.076 & 1.095 & 1.128 \\
\hline & Guangxi & 0.895 & 0.895 & 0.877 & 0.881 & 0.887 \\
\hline \multirow{9}{*}{ West } & Chongqing & 1.000 & 1.000 & 0.929 & 0.915 & 0.894 \\
\hline & Sichuan & 0.853 & 0.853 & 0.834 & 0.834 & 0.833 \\
\hline & Guizhou & 1.000 & 1.000 & 1.051 & 1.064 & 1.085 \\
\hline & Yunnan & 0.622 & 0.622 & 0.495 & 0.497 & 0.503 \\
\hline & Shaanxi & 1.000 & 1.000 & 1.023 & 1.027 & 1.035 \\
\hline & Gansu & 1.000 & 1.000 & 1.038 & 1.049 & 1.069 \\
\hline & Qinghai & 1.000 & 1.000 & 1.159 & 1.201 & 1.280 \\
\hline & Ningxia & 1.000 & 1.000 & 1.042 & 1.054 & 1.076 \\
\hline & Xinjiang & 1.000 & 1.000 & 0.983 & 0.979 & 0.972 \\
\hline Average & & 0.979 & 0.979 & 1.006 & 1.016 & 1.035 \\
\hline
\end{tabular}

TABLe 5: Overall efficiency of east, central, and west China.

\begin{tabular}{|c|c|c|c|c|c|c|}
\hline \multirow{2}{*}{ Area } & \multirow{2}{*}{ Technology } & \multirow{2}{*}{ Model 1} & \multicolumn{4}{|c|}{ Model 8} \\
\hline & & & $\alpha_{i}=0.5$ & $\alpha_{i}=0.1$ & $\alpha_{i}=0.05$ & $\alpha_{i}=0.01$ \\
\hline East & CRS & 0.999 & 0.999 & 1.006 & 1.011 & 1.020 \\
\hline Central & CRS & 0.986 & 0.986 & 1.002 & 1.008 & 1.019 \\
\hline West & CRS & 0.916 & 0.916 & 0.934 & 0.941 & 0.955 \\
\hline East & VRS & 1.000 & 1.000 & 1.043 & 1.057 & 1.082 \\
\hline Central & VRS & 0.989 & 0.989 & 1.016 & 1.024 & 1.039 \\
\hline West & VRS & 0.942 & 0.942 & 0.950 & 0.958 & 0.972 \\
\hline
\end{tabular}

$\left(\Psi_{k}^{\mathrm{Ker}}\right)$ of kerosene utilization in Shanxi is the highest while Hainan has the lowest score. The technical efficiency score $\left(\Psi_{k}^{\text {Die }}\right)$ of diesel utilization in Heilongjiang is the highest while Yunnan has the lowest score. The technical efficiency score $\left(\Psi_{k}^{c}\right)$ of carbon emissions in Qinghai is the highest while Yunnan has the lowest score.

The average $\Psi_{k}^{\mathrm{ES}}, \Psi_{k}^{\mathrm{Gas}}, \Psi_{k}^{\mathrm{Ker}}, \Psi_{k}^{\mathrm{Die}}$, and $\Psi_{k}^{c}$ under CRS are $0.745,0.673,0.618,0.877$, and 0.772 , respectively, which implies that the technical inefficiencies of energy utilization and carbon emissions $\left(\Psi_{k}^{\mathrm{ES}}\right)$ in transportation are mainly due to the lower technical efficiency of gasoline utilization $\left(\Psi_{k}^{\text {Gas }}\right)$ and the lower technical efficiency of kerosene utilization $\left(\Psi_{k}^{\mathrm{Ker}}\right)$.
Table 7 shows that the pure technical efficiency score $\left(\Psi_{k}^{\mathrm{ES}}\right)$ of energy utilization and carbon emissions in Qinghai is the highest while Yunnan has the lowest score. The results are consistent with those obtained from model (8) under the assumption of VRS. There is no pure technical superefficient province of gasoline utilization or kerosene utilization. The pure technical efficiency score $\left(\Psi_{k}^{\mathrm{Gas}}\right)$ of gasoline utilization in Heilongjiang is the lowest, and the pure technical efficiency score $\left(\Psi_{k}^{\mathrm{Ker}}\right)$ of kerosene utilization in Yunnan is the lowest. The pure technical efficiency score $\left(\Psi_{k}^{\text {Die }}\right)$ of diesel utilization in Heilongjiang is the highest while Yunnan has the lowest score. The pure technical efficiency score $\left(\Psi_{k}^{c}\right)$ of 
TABle 6: PEE and PCEE (assuming CRS).

\begin{tabular}{lcccccc}
\hline Area & Province & $\Psi_{k}^{\mathrm{ES}}$ & $\Psi_{k}^{\text {Gas }}$ & $\Psi_{k}^{\text {Ker }}$ & $\Psi_{k}^{\text {Die }}$ & $\Psi_{k}^{c}$ \\
\hline \multirow{6}{*}{ East } & Beijing & 0.455 & 0.448 & 0.180 & 0.835 & 0.418 \\
& Tianjin & 1.019 & 1.000 & 1.000 & 1.000 & 1.037 \\
& Hebei & 1.055 & 1.000 & 1.000 & 1.000 & 1.109 \\
& Liaoning & 1.047 & 1.000 & 1.000 & 1.000 & 1.095 \\
& Shanghai & 1.083 & 1.000 & 1.000 & 1.000 & 1.165 \\
& Jiangsu & 0.520 & 0.170 & 0.400 & 0.877 & 0.551 \\
& Zhejiang & 0.510 & 0.155 & 0.160 & 1.086 & 0.543 \\
& Fujian & 0.621 & 0.326 & 0.626 & 0.780 & 0.661 \\
& Shandong & 1.052 & 1.000 & 1.000 & 1.000 & 1.103 \\
& Guangdong & 0.728 & 0.497 & 0.878 & 0.629 & 0.788 \\
& Hainan & 0.437 & 0.460 & 0.060 & 1.017 & 0.355 \\
\hline \multirow{4}{*}{ Central } & Shanxi & 0.709 & 0.676 & 1.179 & 0.510 & 0.634 \\
& Nei Mongol & 0.560 & 0.170 & 0.837 & 0.890 & 0.480 \\
& Jilin & 0.611 & 0.886 & 0.969 & 0.640 & 0.394 \\
& Heilongiang & 0.469 & 0.130 & 0.101 & 1.573 & 0.320 \\
& Anhui & 1.043 & 1.000 & 1.000 & 1.000 & 1.086 \\
& Jiangxi & 1.046 & 1.000 & 1.000 & 1.000 & 1.092 \\
& Henan & 0.970 & 1.351 & 0.313 & 0.945 & 1.075 \\
& Hubei & 0.537 & 0.383 & 0.235 & 0.842 & 0.583 \\
& Hunan & 1.079 & 1.000 & 1.000 & 1.000 & 1.157 \\
& Guangxi & 0.511 & 0.385 & 0.155 & 0.673 & 0.615 \\
\hline \multirow{4}{*}{ Average } & Chongqing & 0.447 & 0.808 & 0.257 & 0.372 & 0.420 \\
& Sichuan & 0.429 & 0.197 & 0.062 & 0.906 & 0.464 \\
& Guizhou & 1.062 & 1.000 & 1.000 & 1.000 & 1.124 \\
& Yunnan & 0.254 & 0.206 & 0.087 & 0.303 & 0.309 \\
& Shaanxi & 0.771 & 0.527 & 0.245 & 1.053 & 0.928 \\
& Gansu & 1.024 & 1.000 & 1.000 & 1.000 & 1.049 \\
& Qinghai & 1.104 & 1.000 & 1.000 & 1.000 & 1.208 \\
& Ningxia & 0.860 & 1.000 & - & 1.000 & 1.054 \\
& Xinjiang & 0.332 & 0.412 & 0.170 & 0.375 & 0.346 \\
\hline & 0.745 & 0.673 & 0.618 & 0.877 & 0.772 \\
\hline & & & & & & \\
& & &
\end{tabular}

carbon emissions in Qinghai is the highest while Yunnan has the lowest score.

The average $\Psi_{k}^{\mathrm{ES}}, \Psi_{k}^{\mathrm{Gas}}, \Psi_{k}^{\mathrm{Ker}}, \Psi_{k}^{\mathrm{Die}}$, and $\Psi_{k}^{c}$ under VRS are $0.833,0.741,0.697,0.966,0.869$, respectively, which implies that the pure technical inefficiencies of energy utilization and carbon emissions ( $\Psi_{k}^{\mathrm{Gas}}$ ) in transportation are mainly due to the lower pure technical efficiency of gasoline utilization $\left(\Psi_{k}^{\text {Gas }}\right)$ and the lower pure technical efficiency of kerosene utilization $\left(\Psi_{k}^{\mathrm{Ker}}\right)$.

As shown in Table 8, under both CRS and VRS, the ECEE $\left(\Psi_{k}^{\mathrm{ES}}\right)$ of the eastern area is the best while the western area is the worst. The results are consistent with those obtained from model (8). The PCEE ( $\left.\Psi_{k}^{c}\right)$ of the eastern area is also the best under both CRS and VRS. However, the rankings of the central area and the western area are different under different assumptions of production technology. The PEE $\left(\Psi_{k}^{\mathrm{Gas}}, \Psi_{k}^{\mathrm{Ker}}\right.$, or $\left.\Psi_{k}^{\mathrm{Die}}\right)$ of the eastern area is not always the highest in mainland China. For instance, the eastern area has the lowest technical efficiency score of gasoline utilization.

3.3. Discussion and Suggestion. The uncertainty of carbon emissions can significantly affect the results of efficiency evaluation. Therefore, decision-makers should take uncertain carbon emissions into account when they measure the performance of RTS $[54,55]$. The risk criterion also has
TABle 7: PEE and PCEE (assuming VRS).

\begin{tabular}{lcccccc}
\hline Area & Province & $\Psi_{k}^{\mathrm{ES}}$ & $\Psi_{k}^{\text {Gas }}$ & $\Psi_{k}^{\text {Ker }}$ & $\Psi_{k}^{\text {Die }}$ & $\Psi_{k}^{c}$ \\
\hline \multirow{6}{*}{ East } & Beijing & 0.560 & 0.472 & 0.180 & 1.164 & 0.508 \\
& Tianjin & 1.019 & 1.000 & 1.000 & 1.000 & 1.037 \\
& Hebei & 1.055 & 1.000 & 1.000 & 1.000 & 1.109 \\
& Liaoning & 1.047 & 1.000 & 1.000 & 1.000 & 1.095 \\
& Shanghai & 1.083 & 1.000 & 1.000 & 1.000 & 1.165 \\
& Jiangsu & 1.051 & 1.000 & 1.000 & 1.000 & 1.102 \\
& Zhejiang & 0.517 & 0.162 & 0.151 & 1.101 & 0.553 \\
& Fujian & 0.631 & 0.329 & 0.630 & 0.797 & 0.671 \\
& Shandong & 1.052 & 1.000 & 1.000 & 1.000 & 1.103 \\
& Guangdong & 1.063 & 1.000 & 1.000 & 1.000 & 1.125 \\
& Hainan & 1.021 & 1.000 & 1.000 & 1.000 & 1.043 \\
\hline \multirow{4}{*}{ Central } & Shanxi & 1.041 & 1.000 & 1.000 & 1.000 & 1.082 \\
& Nei Mongol & 0.679 & 0.343 & 0.547 & 1.313 & 0.613 \\
& Jilin & 0.653 & 0.921 & 0.681 & 0.851 & 0.489 \\
& Heilongjiang & 0.583 & 0.123 & 0.133 & 1.997 & 0.393 \\
& Anhui & 1.043 & 1.000 & 1.000 & 1.000 & 1.086 \\
& Jiangxi & 1.046 & 1.000 & 1.000 & 1.000 & 1.092 \\
& Henan & 1.037 & 1.000 & 1.000 & 1.000 & 1.075 \\
& Hubei & 0.720 & 0.448 & 0.703 & 0.801 & 0.785 \\
& Hunan & 1.079 & 1.000 & 1.000 & 1.000 & 1.157 \\
& Guangxi & 0.542 & 0.398 & 0.160 & 0.723 & 0.653 \\
\hline \multirow{4}{*}{ Avest } & Chongqing & 0.492 & 0.714 & 0.370 & 0.409 & 0.490 \\
& Sichuan & 0.454 & 0.206 & 0.058 & 0.970 & 0.490 \\
& Guizhou & 1.062 & 1.000 & 1.000 & 1.000 & 1.124 \\
& Yunnan & 0.305 & 0.277 & 0.052 & 0.372 & 0.376 \\
& Shaanxi & 0.778 & 0.523 & 0.255 & 1.063 & 0.937 \\
& Gansu & 1.024 & 1.000 & 1.000 & 1.000 & 1.049 \\
& Qinghai & 1.104 & 1.000 & 1.000 & 1.000 & 1.208 \\
& Ningxia & 0.860 & 1.000 & - & 1.000 & 1.054 \\
& Xinjiang & 0.380 & 0.327 & 0.307 & 0.421 & 0.408 \\
\hline & & 0.833 & 0.741 & 0.697 & 0.966 & 0.869 \\
\hline & & & & & & \\
& & &
\end{tabular}

effects on the results of efficiency evaluation. Hence, a scientific risk criterion is required when decision-makers measure the performance of DMUs using the proposed chance-constrained DEA models.

The performance of Yunnan's transportation system is the worst in mainland China. It has the lowest overall efficiency scores (the technical efficiency score and the pure technical efficiency score), the lowest pure technical efficiency score of kerosene utilization, the lowest efficiency scores (the technical efficiency score and the pure technical efficiency score) of diesel utilization, and the lowest efficiency scores (the technical efficiency score and the pure technical efficiency score) of carbon emissions. Therefore, Yunnan should put forth the greatest possible effort to increase the efficiency of its transportation system. The transportation system of Heilongiiang should make every effort to increase its efficiency of gasoline utilization. The transportation system of Hainan should put forth its best effort to increase its technical efficiency of kerosene utilization.

In China, the unbalanced regional development of the ECEE in transportation corresponds with the unbalanced regional economic development. East China performs better than central China, and central China performs better than west China. Hence, China should try its best to improve the performance of RTS in the western area. 
TABLE 8: PEE and PCEE of east, central, and west China.

\begin{tabular}{lccccr}
\hline Area & Technology & $\Psi_{k}^{\mathrm{ES}}$ & $\Psi_{k}^{\text {Gas }}$ & $\Psi_{k}^{\text {Ker }}$ & $\Psi_{k}^{\text {Die }}$ \\
\hline East & CRS & 0.775 & 0.641 & 0.664 & 0.929 \\
Central & CRS & 0.754 & 0.698 & 0.679 & 0.907 \\
West & CRS & 0.698 & 0.683 & 0.478 & 0.779 \\
East & VRS & 0.918 & 0.815 & 0.815 & 0.743 \\
Central & VRS & 0.842 & 0.723 & 0.722 & 0.767 \\
West & VRS & 0.718 & 0.672 & 0.505 & 0.956 \\
\hline
\end{tabular}



FIgURE 2: The potential energy savings and the potential carbon emission cuts.

Figure 2 shows the potential cuts in each kind of energy and the potential decreases in carbon emissions of each inefficient regional transportation system under the assumption of CRS. It is noteworthy that there are twelve efficient DMUs, i.e., Tianjin, Hebei, Liaoning, Shanghai, Shandong, Anhui, Jiangxi, Hunan, Guizhou, Gansu, Qinghai, and Ningxia (as shown in Table 6). It can be observed that the eastern area (especially, Jiangsu, Zhejiang, and Guangdong) can save many energy fuels and reduce lots of carbon emissions as the eastern area is the largest transportation fuel consumer and the largest carbon emitter in the three areas. Hence, China should also improve the efficiency of RTS in the eastern area.

\section{Conclusion}

This study proposes chance-constrained DEA models to estimate the energy and carbon emission efficiency (ECEE) of regional transportation systems (RTS) considering uncertain carbon emissions. The overall efficiency of thirty regional transportation systems in mainland China is calculated using the radial chance-constrained DEA model. We prove that the radial deterministic DEA model is only a particular case of the radial chance-constrained DEA model. The pure energy efficiency (PEE) and the pure carbon emission efficiency (PCEE) of the thirty regional transportation systems are estimated using the proposed nonradial chance-constrained DEA model. We prove that this model can provide more valuable information for decisionmakers, i.e., how to save each transportation fuel and reduce carbon emissions. We find that most of China's regional transportation systems have low energy and carbon emission efficiency and the inefficiencies are mainly due to the lower gasoline utilization efficiency and the lower kerosene utilization efficiency.

We suggest that (1) China should try its best to improve the performance of the regional transportation systems in the western area because its efficiency is the lowest; (2) China should also improve the performance of the regional transportation systems in the eastern area because the eastern area can save many energy fuels and reduce lots of carbon emissions (especially, Jiangsu, Zhejiang, and Guangdong).

Measuring the energy and carbon emission efficiency (ECEE) of regional transportation systems is an important and hot topic. The results of this study are helpful for the Chinese government to set up different policies for different RTS to improve their ECEE. In fact, the proposed approaches can be also applied to measure the RTS in other countries. In addition, we can measure the ECEE of RTS considering other uncertain inputs and outputs.

\section{Data Availability}

The research data used to support the findings of this study are available from the corresponding author upon request.

\section{Conflicts of Interest}

The authors declare that there are no conflicts of interest regarding the publication of this paper. 


\section{Authors' Contributions}

Jianwei Ren and Chunhua Chen were responsible for the conceptualization of the study; Jianwei Ren and Jiewei Zhang curated the data; Jianwei Ren was responsible for funding acquisition; , Jianwei Ren and Chunhua Chen was responsible for methodology; Software, Bin Gao and Chunhua Chen provided software; Jianwei Ren, Jiewei Zhang, and Chunhua Chen wrote the original draft; Bin Gao and Chunhua Chen performed reviewing and editing.

\section{Acknowledgments}

This research was funded by the National Natural Science Foundation of China (Grant no. 71862026), the China Postdoctoral Science Foundation (Grant no. 2018T110209), the Natural Science Foundation of Inner Mongolia (Grant no. 2018MS07006), and the State Scholarship Fund of China Scholarship Council (Grant no. 20180815502).

\section{References}

[1] Y. Fan, C. Fang, and Q. Zhang, "Coupling coordinated development between social economy and ecological environment in Chinese provincial capital cities-assessment and policy implications," Journal of Cleaner Production, vol. 229, pp. 289-298, 2019.

[2] Y. Yang, L. Chen, F. Jia, and Z. Xu, "Complementarity of circular economy practices: an empirical analysis of Chinese manufacturers," International Journal of Production Research, vol. 57, no. 20, 2019.

[3] International Monetary Fund, IMF Report about China, International Monetary Fund, Washington, DC, USA, 2019, https://www.imf.org/external/datamapper/NGDPD@WEO/ OEMDC/ADVEC/WEOWORLD.

[4] J. Zheng, Z. Mi, D. M. Coffman et al., "Regional development and carbon emissions in China," Energy Economics, vol. 81, pp. 25-36, 2019.

[5] L. Liu, P. Wang, and T. Wu, "The role of nongovernmental organizations in China's climate change governance," Wiley Interdisciplinary Reviews: Climate Change, vol. 8, no. 6, pp. 1-16, 2017.

[6] H. Duan, J. Mo, Y. Fan, and S. Wang, "Achieving China's energy and climate policy targets in 2030 under multiple uncertainties," Energy Economics, vol. 70, pp. 45-60, 2018.

[7] R. Xie, L. Huang, B. Tian, and J. Fang, "Differences in changes in carbon dioxide emissions among China's transportation subsectors: a structural decomposition analysis," Emerging Markets Finance and Trade, vol. 55, no. 6, pp. 1294-1311, 2019.

[8] B. Wang, Y. Sun, Q. Chen, and Z. Wang, "Determinants analysis of carbon dioxide emissions in passenger and freight transportation sectors in China," Structural Change and Economic Dynamics, vol. 47, pp. 127-132, 2018.

[9] R.-Q. Yuan, X. Tao, and X.-L. Yang, " $\mathrm{CO}_{2}$ emission of urban passenger transportation in China from 2000 to 2014," Advances in Climate Change Research, vol. 10, no. 1, pp. 59-67, 2019.

[10] E. Asmare and A. Begashaw, "Review on parametric and nonparametric methods of efficiency analysis," Biostatistics and Bioinformatics, vol. 2, no. 2, pp. 1-7, 2018.

[11] M.-M. Yu and L.-H. Chen, "Evaluation of efficiency and technological bias of tourist hotels by a meta-frontier DEA model," Journal of the Operational Research Society, vol. 12, pp. 1-15, 2019.

[12] M. M. Yu and E. Bulut, "Performance evaluation of BDI forecasting models cross efficiency, the directional distance function and the AVs utility function," International Journal Of Transport Economics, vol. 46, pp. 177-199, 2019.

[13] A. Emrouznejad, R. Banker, and L. Neralić, "Advances in data envelopment analysis: celebrating the 40th anniversary of DEA and the 100th anniversary of professor abraham charnes' birthday," European Journal of Operational Research, vol. 278, no. 2, pp. 365-367, 2019.

[14] A. Charnes, W. W. Cooper, and E. Rhodes, "Measuring the efficiency of decision making units," European Journal of Operational Research, vol. 2, no. 6, pp. 429-444, 1978.

[15] R. D. Banker, A. Charnes, and W. W. Cooper, "Some models for estimating technical and scale inefficiencies in data envelopment analysis," Management Science, vol. 30, no. 9, pp. 1078-1092, 1984.

[16] S. Lozano and G. Villa, "Data envelopment analysis of integervalued inputs and outputs," Computers \& Operations Research, vol. 33, no. 10, pp. 3004-3014, 2005.

[17] P. Andersen and N. C. Petersen, "A procedure for ranking efficient units in data envelopment analysis," Management Science, vol. 39, no. 10, pp. 1261-1264, 1993.

[18] Z. X. Ma and C. Y. Zhao, "Measure method for efficiency of generalized DEA," Journal of Systems Engineering and Electronics, vol. 38, pp. 2572-2585, 2016.

[19] K. Tone, "A slacks-based measure of super-efficiency in data envelopment analysis," European Journal of Operational Research, vol. 143, no. 1, pp. 32-41, 2002.

[20] R. Mahmoudi, S.-N. Shetab-Boushehri, S. R. Hejazi, A. Emrouznejad, and P. Rajabi, "A hybrid egalitarian bargaining game-DEA and sustainable network design approach for evaluating, selecting and scheduling urban road construction projects," Transportation Research Part E: Logistics and Transportation Review, vol. 130, pp. 161-183, 2019.

[21] A. Ebrahimnejad, M. Tavana, S. H. Nasseri, and O. Gholami, "A new method for solving dual DEA problems with fuzzy stochastic data," International Journal of Information Technology \& Decision Making, vol. 18, no. 1, pp. 147-170, 2019.

[22] R. Ramanathan, "A holistic approach to compare energy efficiencies of different transport modes," Energy Policy, vol. 28, no. 11, pp. 743-747, 2000.

[23] J.-L. Hu and S.-C. Wang, "Total-factor energy efficiency of regions in China," Energy Policy, vol. 34, no. 17, pp. 32063217, 2006.

[24] J. Wu, M. Li, Q. Zhu, Z. Zhou, and L. Liang, "Energy and environmental efficiency measurement of China's industrial sectors: a DEA model with non-homogeneous inputs and outputs," Energy Economics, vol. 78, pp. 468-480, 2019.

[25] Z. Geng, R. Zeng, Y. Han, Y. Zhong, and H. Fu, "Energy efficiency evaluation and energy saving based on DEA integrated affinity propagation clustering: case study of complex petrochemical industries," Energy, vol. 179, pp. 863-875, 2019.

[26] Y. Choi, N. Zhang, and P. Zhou, "Efficiency and abatement costs of energy-related $\mathrm{CO}_{2}$ emissions in China: a slacks-based efficiency measure," Applied Energy, vol. 98, pp. 198-208, 2012.

[27] P. Zhou, B. W. Ang, and K. L. Poh, "Slacks-based efficiency measures for modeling environmental performance," Ecological Economics, vol. 60, no. 1, pp. 111-118, 2006.

[28] P. Zhou, B. W. Ang, and K. L. Poh, "Measuring environmental performance under different environmental DEA technologies," Energy Economics, vol. 30, no. 1, pp. 1-14, 2008. 
[29] Q. Wang, P. Zhou, and D. Zhou, "Efficiency measurement with carbon dioxide emissions: the case of China," Applied Energy, vol. 90, no. 1, pp. 161-166, 2012.

[30] C. Wei, J. Ni, and L. Du, "Regional allocation of carbon dioxide abatement in China," China Economic Review, vol. 23, no. 3, pp. 552-565, 2012.

[31] K. Wang, S. Yu, and W. Zhang, "China's regional energy and environmental efficiency: a DEA window analysis based dynamic evaluation," Mathematical and Computer Modelling, vol. 58, no. 5, pp. 1117-1127, 2013.

[32] X. Guo, C.-C. Lu, J.-H. Lee, and Y.-H. Chiu, “Applying the dynamic DEA model to evaluate the energy efficiency of OECD countries and China," Energy, vol. 134, pp. 392-399, 2017.

[33] S. Cheng, W. Liu, and K. Lu, "Economic growth effect and optimal carbon emissions under China's carbon emissions reduction policy: a time substitution DEA approach," Sustainability, vol. 10, pp. 1-23, 2018.

[34] J.-F. Chu, J. Wu, and M.-L. Song, "An SBM-DEA model with parallel computing design for environmental efficiency evaluation in the big data context: a transportation system application," Annals of Operations Research, vol. 270, no. 1, pp. 105-124, 2018.

[35] Q. Cui, "Investigating the airlines emission reduction through carbon trading under CNG2020 strategy via a network weak disposability DEA," Energy, vol. 180, pp. 763-771, 2019.

[36] B. Djordjević and E. Krmac, "Evaluation of energy-environment efficiency of european transport sectors: non-radial DEA and TOPSIS approach," Energies, vol. 12, pp. 1-27, 2019.

[37] Z. Zhou, G. Xu, C. Wang, and J. Wu, "Modeling undesirable output with a DEA approach based on an exponential transformation: an application to measure the energy efficiency of Chinese industry," Journal of Cleaner Production, vol. 236, pp. 1-11, 2019.

[38] H. Omrani, K. Shafaat, and A. Alizadeh, "Integrated data envelopment analysis and cooperative game for evaluating energy efficiency of transportation sector: a case of Iran," Annals of Operations Research, vol. 274, no. 1, pp. 471-499, 2019.

[39] Y. Zha, L. Zhao, and Y. Bian, "Measuring regional efficiency of energy and carbon dioxide emissions in China: a chance constrained DEA approach," Computers \& Operations Research, vol. 66, pp. 351-361, 2016.

[40] C. Wu, Y. Li, Q. Liu, and K. Wang, "A stochastic DEA model considering undesirable outputs with weak disposability," Mathematical and Computer Modelling, vol. 58, no. 5, pp. 980-989, 2013.

[41] J. Jin, D. Zhou, and P. Zhou, "Measuring environmental performance with stochastic environmental DEA: the case of APEC economies," Economic Modelling, vol. 38, pp. 80-86, 2014.

[42] Z. Chen, P. Wanke, J. J. M. Antunes, and N. Zhang, "Chinese airline efficiency under $\mathrm{CO}_{2}$ emissions and flight delays: a stochastic network DEA model," Energy Economics, vol. 68, pp. 89-108, 2017.

[43] Y. Zhou, L. Li, R. Sun, Z. Gong, M. Bai, and G. Wei, "Haze influencing factors: a data envelopment analysis approach," International Journal of Environmental Research and Public Health, vol. 16, no. 6, pp. 1-16, 2019.

[44] G. Liu, Y. Liu, and C. Zhang, "Factor allocation, economic growth and unbalanced regional development in China," The World Economy, vol. 41, no. 9, pp. 2439-2463, 2018.
[45] R. Färe and S. Grosskopf, "Modeling undesirable factors in efficiency evaluation: comment," European Journal of Operational Research, vol. 157, no. 1, pp. 242-245, 2004.

[46] B. K. Sahoo, M. Luptacik, and B. Mahlberg, "Alternative measures of environmental technology structure in DEA: an application," European Journal of Operational Research, vol. 215, no. 3, pp. 750-762, 2011.

[47] Y. Yang, K. Wei, R. Kang, and S. Wang, "Multi-objective chance constrained programming of spare parts based on uncertainty theory," IEEE Access, vol. 6, pp. 50049-50054, 2018.

[48] M. Izadikhah, M. Azadi, V. Shokri Kahi, and R. Farzipoor Saen, "Developing a new chance constrained NDEA model to measure the performance of humanitarian supply chains," International Journal of Production Research, vol. 57, no. 3, pp. 662-682, 2019.

[49] National Bureau of Statistics of China, China Energy Statistical Yearbook 2014-2018, National Bureau of Statistics of China, Beijing, China, 2019, https://www.chinayearbooks. com/tags/china-energy-statistical-yearbook.

[50] R. G. Dyson, R. Allen, A. S. Camanho, V. V. Podinovski, C. S. Sarrico, and E. A. Shale, "Pitfalls and protocols in DEA," European Journal of Operational Research, vol. 132, no. 2, pp. 245-259, 2001.

[51] National Bureau of Statistics of China, China Statistical Yearbook, National Bureau of Statistics of China, Beijing, China, 2018, http://www.stats.gov.cn/tjsj/ndsj/2018/indexeh. html.

[52] T. Zhang, L. Q. Chen, R. Wang et al., "The influencing factors of industrial carbon emissions in the context of undertaking industrial transfer in Anhui province, China," Applied Ecology and Environmental Research, vol. 17, no. 2, pp. 4205-4227, 2019.

[53] IPCC, IPCC guidelines for National Greenhouse Gas Inventories, Geneva, Switzerland, 2006, https://www.ipcc-nggip. iges.or.jp/public/2006gl/.

[54] H. You and X. Zhang, "Ecoefficiency of intensive agricultural production and its influencing factors in China: an application of DEA-tobit analysis," Discrete Dynamics in Nature and Society, vol. 2016, Article ID 4786090, 14 pages, 2016.

[55] Q. Hou, M. Wang, and X. Zhou, "Improved DEA cross efficiency evaluation method based on ideal and anti-ideal points," Discrete Dynamics in Nature and Society, vol. 2018, Article ID 1604298, 9 pages, 2018. 